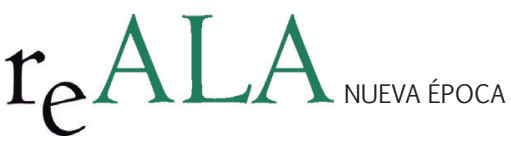

REALA, n 2, julio-diciembre 2014, ISSN: 1989-8975

DOI: http://dx.doi.org/10.24965/reala.voi2.10190

\title{
Nuevo régimen jurídico de los servicios públicos locales, tras la Ley núm. 27/2013, de 27 de diciembre, de racionalización y sostenibilidad de la Administración Local
}

\author{
Iñigo del Guayo Castiella \\ Catedrático de Derecho Administrativo. Universidad de Almería \\ iguayo@ual.es
}

Recibido: 17 de abril 2013 Aceptado: II de junio 2014

\begin{abstract}
Resumen
La versión original de la Ley Reguladora de las Bases de Régimen Local de 1985 y del Texto Refundido de las Disposiciones vigentes en materia de Régimen Local de 1986, no establecían una clara distinción entre competencias locales, servicios públicos locales y servicios esenciales reservados. La reforma llevada a cabo en 2003 proporcionó un poco de claridad, pero no excesiva. Este artículo analiza las reformas llevadas a cabo en materia de servicios públicos locales por la Ley núm. 27/2013, de 27 de diciembre, de racionalización y sostenibilidad de la Administración Local: se modifica la lista de servicios mínimos municipales; se refuerza el papel de las Diputaciones en la gestión de esos servicios mínimos; se introducen modificaciones en las formas de gestión de los servicios públicos; se modifica el precepto relativo a la iniciativa económica local y a las reservas locales; si una corporación local no cumple sus obligaciones financieras debe proceder a la gestión integrada o coordinada de los servicios obligatorios que presta la entidad local para reducir sus costes; y se establece la obligación de proceder a la determinación del coste efectivo de los servicios, antes del 1 de noviembre de cada año.
\end{abstract}

Palabras clave

Servicios obligatorios locales, gestión de servicios locales, servicios esenciales reservados.

\section{New Legal Regime for Local Public Services, Following Act no. 27/2013, of 27 December, Rationalization and Sustainability of Local Government}

\footnotetext{
Abstract

The original version of the Local Administration Act of 1985 and its development of 1986 did not establish a clear distinction between local competences, local public services and reserved essential services. The reform carried out in 2003 provided some clarity, but not excessive. This article analyses the reforms undertaken in the field of local public services by Act No 27, of 27 December 2013, on the rationalization and sustainability of local government: the list of minimum municipal services is amended; the role of Province Governments in managing these minimum services is reinforced; changes in the forms of managing services are introduced; it amends the provision relating to local economic initiative and local reserves; by local authority does not meet its financial obligations it must arrange an integrated or coordinated management of mandatory services provided local authorities, in order to reduce costs; and it imposes upon Local Governments the obligation to determinate the effective costs of the services by 1 November each year.
}

Key words

Mandatory local services, management of local services, essential reserved services. 


\section{PLANTEAMIENTO}

La Ley núm. 27/2013, de 27 de diciembre, de racionalización y sostenibilidad de la Administración Local (en adelante, LRSAL) incluye algunas importantes reformas en materia de servicios públicos locales: a) se modifica la lista de servicios mínimos municipales del art. 26 de la Ley núm. 7/1985, de 18 de abril, reguladora de las bases de Régimen local (en adelante, LRBRL); b) se refuerza el papel de las Diputaciones en la gestión de esos servicios mínimos; c) se introducen modificaciones en las formas de gestión de los servicios públicos en el art. 85 y 85 ter de la LRBRL; d) se modifica el precepto relativo a la iniciativa económica local y a la reservas locales (art. 86 de la LRBRL); e) se modifica el apartado segundo del artículo 97 del texto refundido de las Disposiciones Legales vigentes en materia de Régimen Local, aprobado por el Real Decreto Legislativo 781/1986, de 18 de abril (en adelante, TRRL); f) si una corporación local incumple el objetivo de estabilidad presupuestaria o de deuda pública, o incumple la regla de gasto, el plan económico-financiero debe incluir, entre otras, la gestión integrada o coordinada de los servicios obligatorios que presta la entidad local para reducir sus costes'; y g) se establece la obligación de proceder a la determinación del efectivo coste de todos y cada uno de los servicios, antes del 1 de

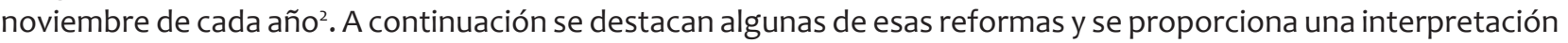
de su sentido y consecuencias.

El tema tiene relevancia, tanto para las entidades locales, como para sus vecinos, pues una mayor precisión legal sobre cuáles son los servicios públicos locales y sobre el régimen de su gestión facilita la acción administrativa y proporciona claridad a los ciudadanos acerca de qué pueden exigir a quién. La Exposición de Motivos de la LRSAL hace referencia a esa relevancia, cuando critica el modelo competencial de la LRBRL, entre otras cosas porque implicaba, a veces, «duplicidad en la prestación de servicios» o, en otras ocasiones «que los Ayuntamientos presten servicios sin un título competencial específico que les habilite y sin contar con los recursos adecuados para ello». En definitiva, para el autor de la Exposición de Motivos, «este sistema competencial municipal hace que se difumine la responsabilidad de los gobiernos locales en su ejercicio y se confunda con los ámbitos competenciales propios de otras Administraciones Públicas, generando, en no pocas ocasiones, el desconcierto de los ciudadanos que desconocen cuál es la Administración responsable de los servicios públicos».

\section{INICIATIVA ECONÓMICA LOCAL Y SERVICIOS PÚBLICOS LOCALES}

El sector público económico (estatal, autonómico y local) al que se refiere el art. 128, 2, de la CE, opera en dos principales ámbitos: los servicios públicos de naturaleza económica y las actividades económicas que formalmente no resultan referibles al concepto estricto de servicio público. Aquel precepto constitucional dice tres cosas: en primer lugar, que los poderes públicos están habilitados para intervenir en la economía; en segundo lugar, que la ley puede reservar al sector público recursos o servicios esenciales; en tercer lugar, que los poderes públicos pueden intervenir en las empresas cuando lo exija el interés general. De aquí derivan las dos grandes modalidades que puede revestir la actividad pública económica, una en ámbitos no publificados donde el sector público debe concurrir como un agente más del mercado de que se trate (siempre que eso sea verdaderamente posible) y otra relativa a la intervención en ámbitos reservados a favor del sector público (servicios públicos).

Esas dos modalidades se cumplen también en la esfera local. En primer lugar, las entidades locales son titulares de determinados servicios públicos que la ley ha reservado a su favor. En la organización de tales servicios gozan las entidades locales de libertad -con algunos límites en determinados casos- para gestionarlos directamente (con exclusión de las empresas particulares) o para contratar la gestión con terceros. En segundo lugar, las entidades locales pueden intervenir en la economía (en sectores no publificados a su favor), mediante, por ejemplo, la constitución de empresas públicas para el desempeño de cuantas actividades y servicios reputen las entidades locales convenientes u oportunas -y así lo acrediten-, con objeto de satisfacer las necesidades de los vecinos y que se designan a veces como servicios económicos para distinguirlos de los servicios públicos en sentido estricto. En esta segunda modalidad las entidades locales no excluyen a los particulares del funcionamiento en el sector de que se trate ni pueden gozar de privilegio alguno.

Las versiones originales de la LRBRL de 1985 y del TRRL de 1986 confundían frecuentemente ambos ámbitos de actuación de los entes locales. Las sucesivas reformas no aclararon el panorama, sino que con frecuencia lo oscurecieron aún más. Los intentos de trazar paralelismos entre el sector público económico local, tal y como se configura en la CE y la LRBRL, con los antiguos conceptos de la municipalización (o provincialización) de servicios, con o sin monopolio, no hacen sino aumentar la confusión. Debe aceptarse que el régimen del sector público económico local surgido de la CE es nuevo y no una mera continuidad ${ }^{3}$

\footnotetext{
Nuevo art. 116 bis, 2, letra b, en relación con la DA 15 , ambas de la LRBRL.

Nuevo art. 116 ter de la LRBRL.

Vid. Magaldi Mendaña, N., Los orígenes de la municipalización de servicios en España, INAP, Madrid 2012.
} 
Cuando en este trabajo hablo de la «iniciativa económica local» me quiero referir a todas las actividades o servicios de naturaleza económica que puede llevar a cabo la entidad local, distintos de los servicios públicos económicos. Es decir, que no incluyo la reserva de una actividad o servicio, ni la gestión de un servicio público, dentro del concepto de «iniciativa económica local». En este trabajo, por tanto, el concepto de «iniciativa económica local» tiene carácter residual, porque está constituido por todas las actividades económicas distintas de los servicios públicos económicos. Esto realza la importancia de determinar con precisión qué es un servicio público local, pues también ayuda a dejar fuera todas las demás actividades económicas que no son servicios públicos económicos4.

\section{NUEVOS LÍMITES PARA EL EJERCICIO DE INICIATIVAS ECONÓMICAS LOCALES}

La versión original del art. 86, 1, de la LRBRL era una reiteración de lo dispuesto en el art. 128, 2, primera frase, de la CE, una versión local de esa previsión constitucional:

«Las Entidades locales, mediante expediente acreditativo de la conveniencia y oportunidad de la medida, podrán ejercer la iniciativa pública para el ejercicio de actividades económicas conforme al artículo 128.2 de la Constitución».

Este precepto se completa con el art. 96 del TRRL, que establece lo siguiente:

«La iniciativa de las Entidades locales para el ejercicio de actividades económicas, cuando lo sea en régimen de libre concurrencia, podrá recaer sobre cualquier tipo de actividad que sea de utilidad pública y se preste dentro del término municipal y en beneficio de sus habitantes».

El precepto transcrito del TRRL reafirma lo establecido en la versión original del art. 86, 1, LRBRL, pero en el precepto del TRRL hay dos elementos novedosos respecto de la LRBRL, a saber: se aclara expresamente que la iniciativa local puede recaer sobre cualquier actividad de utilidad pública y además se limita la amplitud de las actividades que puede la entidad local emprender a la circunstancia de que se desarrollen en régimen de libre competencia.

Cuando el art. 96 del TRRL habla de «la iniciativa de las Entidades locales para el ejercicio de actividades económicas(...)» utiliza la expresión iniciativa económica local en un sentido amplio, para acoger tanto la iniciativa que da lugar a servicios públicos económicos, como la iniciativa que da lugar a otras actividades económicas distintas de los servicios públicos. No utiliza la expresión iniciativa económica local en el sentido que tiene en este trabajo, más reducido, como la iniciativa que se lleva a cabo fuera del ámbito de los servicios públicos. Sólo a partir de ese sentido amplio se entiende que el precepto añada lo siguiente: «(...) cuando lo sea en régimen de libre concurrencia, podrá recaer sobre cualquier tipo de actividad que sea de utilidad pública y se preste dentro del término municipal y en beneficio de sus habitantes». Lo que quiere decir el artículo es que la iniciativa propia de los servicios públicos sólo puede recaer en actividades susceptibles de ser reservadas, mientras que la otra iniciativa puede recaer en cualquier actividad de utilidad pública, pero ha de llevarse a cabo en régimen de libre concurrencia.

Las cuestiones relativas a la iniciativa municipal en la economía (ámbito, modos, intensidad...) quedaba en consecuencia remitidas -dada la referencia del art. 86, 1, de la LRBRL al art. 128 CE- a los más amplios temas del modelo económico de la CE y del papel que reserva a los poderes públicos en la economía. Aun cuando aquella versión original remitía al art. 128, 2, era fácil deducir que la remisión estaba hecha sólo a la primera frase del precepto constitucional (iniciativa pública en la economía), pero no a la segunda frase (reservas), porque el apartado 3 de la versión original del art. 86 de la LRBRL era el dedicado a las reservas.

La LRSAL modifica el primer apartado del art. 86. Ahora, aun cuando ya no hay ni siquiera remisión al art. 128 , 2, de la CE, debe seguir interpretándose que de las dos modalidades de la acción pública en la economía, contempladas en ese precepto constitucional, el art. 86,1 , de la LRBRL es un trasunto local de la iniciativa pública local en la economía, no de las reservas locales ni, por tanto de los servicios públicos económicos. De acuerdo con la nueva redacción, las Entidades Locales pueden ejercer la iniciativa pública para el desarrollo de actividades económicas, con el límite siguiente: la garantía del «cumplimiento del objetivo de estabilidad presupuestaria y de la sostenibilidad financiera del ejercicio de sus competencias».

En la versión original de la LRBRL, se exigía que la iniciativa económica se llevase a cabo mediante expediente acreditativo de la conveniencia y oportunidad de la medida, pero no se decía nada más. Tras la LRSAL de 2013, la

4 Vid. Sosa Wagner, La gestión de los servicios públicos locales, ed. Civitas, Cizur Menor 2008, 7 a ed.; Ortega Bernardo, J., Competencias, servicios públicos y actividad económica de los municipios (Presupuestos actuales para su delimitación y ejercicio), en «Revista de Administración Pública», núm. 169 (2006), pp. 55-98. 
LRBRL exige que en ese expediente se justifique «que la iniciativa no genera riesgo para la sostenibilidad financiera del conjunto de la Hacienda municipal» y debe «contener un análisis del mercado, relativo a la oferta y a la demanda existente, a la rentabilidad y a los posibles efectos de la actividad local sobre la concurrencia empresarial».

La versión aprobada en la Cortes Generales como apartado 1 del art. 86 de la LRBRL es la que se contenía en el Proyecto remitido por el Gobierno 5 . Se aprobó, por tanto, sin modificaciones. Los anteproyectos que preparó el Gobierno tenían una redacción diferente, dirigida a sujetar a más condiciones el ejercicio de la iniciativa pública en la economía. Concretamente, los Anteproyectos añadían al precepto, lo siguiente:

«En el expediente acreditativo de la conveniencia y oportunidad de la medida habrá de justificarse, en especial, que la entidad local presta todos los servicios mínimos, con arreglo al coste estándar de los servicios, en su caso, establecidos, así como que la iniciativa no genera riesgo para la sostenibilidad financiera del Municipio, ni en lo relativo al mantenimiento de los referidos servicios, ni a la propia actividad fruto de la iniciativa pública».

Como se ve, el autor del Anteproyecto quería ligar la suerte de la iniciativa pública económica a la óptima satisfacción de los servicios públicos municipales. El autor del anteproyecto partía de la premisa (que no es necesariamente falsa) de que la iniciativa económica local, en ámbitos distintos de los servicios públicos o de los servicios esenciales reservados, es un estadio ulterior a la implantación eficiente de los servicios mínimos. En definitiva, el mensaje dirigido a las entidades locales era el siguiente: cuando tenga todos los servicios mínimos bien atendidos, con costes razonables, entonces puede la entidad local desempeñar otras actividades económicas.

Si bien esas exigencias del Anteproyecto no se incluyeron en el Proyecto ni, por ende, en la LRSAL, la nueva versión del art. 86 de la LRBRL sí exige que el expediente contenga un análisis del mercado, relativo a la oferta y a la demanda existente, a la rentabilidad y a los posibles efectos de la actividad local sobre la concurrencia empresarial. No se puede decir que la LRSAL venga a limitar (en contra de la Constitución) la libertad de las entidades locales para llevar a cabo nuevas iniciativas económicas. Por el contrario, la nueva versión de la LRBRL tras la LRSAL viene a concretar qué ha de entenderse por oportunidad y conveniencia. Lógicamente, en el ámbito económico (distinto de los servicios públicos) la oportunidad y la conveniencia no pueden estar desligadas de las leyes económicas, como las que explicita hoy, tras la LRSAL, el apartado 1 del art. 86 la LRBRL.

\section{4. ¿UN PASO HACIA UNA MÁS CLARA DELIMITACIÓN DE LOS DOS ÁMBITOS DE ACTIVIDAD ECONÓMICA DE LAS ENTIDADES LOCALES? SOBRE LA EXIGENCIA DE LIBRE CONCURRENCIA CUANDO LA ENTIDAD LOCAL EJERCITA SU INICIATIVA ECONÓMICA Y SOBRE EL ÓRGANO COMPETENTE PARA APROBAR LA ACTIVIDAD ECONÓMICA}

El apartado 2 de la versión original del art. 86 de la LRBRL decía así:

«Cuando el ejercicio de la actividad se haga en régimen de libre concurrencia, la aprobación definitiva corresponderá al Pleno de la Corporación, que determinará la forma concreta de gestión del servicio».

Como el apartado 1 de ese mismo precepto se refiere a la iniciativa pública para el ejercicio de actividades económicas del art. 128, 2, de la CE y como el apartado 3 trata sobre las reservas locales, hay que interpretar que el apartado 2 versa sobre la iniciativa económica que opera en ámbitos distintos de los servicios reservados (servicios públicos); por consiguiente, el apartado 2 de la versión original del art. 86 de la LRBRL es una especificación relativa a esta iniciativa económica en ámbitos no publificados.

En el contexto del art. 86 de la LRBRL en su conjunto, la previsión establecida en el apartado 2 tenía una cierta lógica, por cuanto sólo era necesaria la aprobación de la Comunidad Autónoma (aprobación contemplada en el art. 86,3 , de la LRBRL) si se pretendía ejercitar en régimen de monopolio un servicio esencial reservado. Ahora bien, ese apartado 2 llevaba a confusión, por cuanto parecía dar a entender que las entidades locales podían establecer que el ejercicio de la actividad económica de que se tratase (fuera de los servicios públicos) no se haría en régimen de libre concurrencia. Frente a esa confusión, ha de reiterarse que las actividades económicas que puede llevar a cabo la entidad local como consecuencia de la iniciativa económica no son actividades tasadas, nunca podrán implicar un monopolio y no son auténticos servicios públicos.

Sorprende el contenido que el autor de la LRBRL dio al apartado 2 del art. 86 LRBRL, porque a contrario sensu parecía admitir que la actividad empresarial de la entidad local no se realizase en régimen de libre concurrencia y porque lo que al principio del párrafo designaba como «actividad» terminaba llamándolo al final «servicio».

5 BOCG, Serie A, núm. 58-1, de 6 de septiembre de 2013. 
Ambas perplejidades podrían explicarse parcial aunque no satisfactoriamente de la manera siguiente: si se entiende que los apartados 1 y 2 del art. 86 de la LRBRL se referían tanto a la iniciativa económica en ámbitos publificados (servicios públicos o reservados), como a la iniciativa en otros sectores económicos, entonces no había inconveniente en aceptar que la actividad no se llevase en régimen de libre concurrencia, porque habría actividades o servicios reservados cuya gestión conforme a la LRBRL podría ser efectivamente monopolística (es decir, que la «actividad» a que se refería el art. 86, 2, de la LRBRL podía ser alguna de las «actividades» del art. 86,3 , en la versión original de la LRBRL); en favor de esa interpretación estaba la circunstancia que el art. 86, 2, de la LRBRL se refería conjuntamente a las actividades reservadas y a los servicios reservados, es decir que podría aceptarse que el apartado 2 se refería a ambos tipos de iniciativa económica local.

Al margen de ese debate, conviene recordar que el propósito del apartado 2 de la versión original del art 86 de la LRBRL era el señalamiento de la autoridad competente para aprobar la actividad: si se trataba de una actividad no constitutiva de servicio público o de un servicio público cuya gestión no va a monopolizarse, la aprobación correspondería al Pleno del Ayuntamiento; si se trataba de un servicio público (es decir, de alguna de las actividades o servicios reservados del art. 86, 3, de la LRBRL) que pretendía gestionarse monopolísticamente, la aprobación se sometía al órgano de Gobierno de la Comunidad Autónoma (argumento: arts. 86, 2 y 86, 3, párrafo 2, de la versión original de la LRBRL, puestos en relación).

La LRSAL ha derogado el apartado 2 del art. 86 de la LRBRL. Su contenido -al menos, parcialmente- ha sido llevado a un nuevo párrafo segundo del art. 86, 1, de la LRBRL, que dice así:

«Corresponde al pleno de la respectiva Corporación local la aprobación del expediente, que determinará la forma concreta de gestión del servicio».

Tras la reforma llevada a cabo por la LRSAL, el art. 86 de la LRBRL ya no dice nada sobre el principio de concurrencia en el caso de la iniciativa pública local, pero debe defenderse su subsistencia, a la luz de la CE y del TFUE. Es más, la supresión de la locución «cuando el ejercicio de la actividad se haga en régimen de libre concurrencia» debería entenderse como una reforma orientada a dejar claro que la iniciativa económica en ámbitos no publificados sólo puede llevarse en régimen de libre concurrencia. Adicionalmente puede recordarse que el art. 96 del TRRL, de una manera velada pero indiscutible, viene a exigir que la iniciativa económica local en sectores no publificados se lleve a cabo en régimen de libre concurrencia, en la forma señalada supra.

En definitiva, aunque no se menciona ya la libre concurrencia en el art. 86, 1, segundo párrafo (añadido por la LRSAL), de la LRBRL, subsiste en ese precepto de la LRBRL la distinción entre la actividad que se lleva a cabo en libre concurrencia y que es aprobada por la Corporación (art. 86, 1, segundo párrafo, de la LRSAL) y la actividad o servicio reservados que, cuando se van a prestar en régimen de monopolio, han de ser aprobados por la Comunidad Autónoma (art. 86, 2, segundo párrafo, de la LRBRL).

Debe darse la bienvenida a la reforma llevada a cabo por la LRSAL en la estructura del art. 86 de la LRBRL. En la versión original, no era claro saber a qué tipo de iniciativa económica se referían los apartados 1 y 2 (si a la iniciativa en ámbitos publificados o a la iniciativa en otros ámbitos económicos no publificados o a ambas). Estaba claro que el apartado 3 versaba sólo sobre las reservas (servicios públicos). Tras la LRSAL, el art. 86 de la LRBRL tiene sólo dos apartados (el contenido del original apartado 2 ha sido parcialmente subsumido en el apartado 1) y puede afirmarse que el apartado 1 versa sobre aquello que este trabajo denomina iniciativa económica local, mientras que el apartado 2 versa sobre las reservas (servicios públicos). La reforma ha introducido un tanto de mayor claridad.

Las actividades económicas fruto de la libre iniciativa local contempladas en el art. 86, 1, LRBRL pueden dar lugar a empresas públicas que las entidades locales crean para el desempeño de actividades que se realizan en concurrencia con los particulares: si no se trata de servicios reservados, esta concurrencia es exigible. También la gestión de los servicios públicos, cuando se lleva a cabo mediante gestión directa, puede dar lugar a la aparición de empresas públicas locales (OAs, EPEs o sociedades mercantiles locales), pero estas empresas públicas tienen un régimen peculiar y distinto de las otras empresas públicas locales (es decir, de aquellas que cree la entidad local en ámbitos distintos de los servicios públicos).

\section{SOBRE LA FORMA DE GESTIÓN DE LAS ACTIVIDADES ECONÓMICAS FRUTO DE LA INICIATIVA ECONÓMICA LOCAL}

El apartado 2 del art. 86 de la versión original de la LRBRL llevaba también a confusión porque al decir que la Corporación determinaría «la forma concreta de gestión del servicio» parecía dar a entender que la iniciativa económica local del art. 86, 1, en ámbitos distintos de los servicios públicos, daba lugar a servicios susceptibles 
de ser gestionados de acuerdo con alguna de la formas específicamente previstas para la gestión de los servicios públicos y, concretamente, susceptibles de ser gestionados de forma indirecta.

La LRSAL ha derogado ese apartado 2 del art. 86, pero la reforma arroja todavía mayor oscuridad sobre el problema planteado en el párrafo anterior. El art. 86, 1, segundo párrafo, de la LRBRL dice ahora que «corresponde al pleno de la respectiva Corporación local la aprobación del expediente, que determinará la forma concreta de gestión del servicio». La expresión final («forma concreta de gestión del servicio») es más propia de la gestión de los servicios públicos y, sin embargo, se ubica en el partado 1 del art. 86 de la LRBRL que versa sobre la iniciativa económica local, distinta del ámbito de los servicios públicos o de los servicios reservados.

El art. 95, apartado 1, del TRRL dice así: «Los servicios públicos locales, incluso los ejercidos en virtud de la iniciativa pública prevista en el artículo 86 de la Ley 7/1985, de 2 de abril, podrán ser gestionados directa o indirectamente. Sin embargo, los servicios que impliquen ejercicio de autoridad sólo podrán ser ejercitados por gestión directa». Para entenderlo, hay que aceptar que el precepto descansa en dos premisas: en primer lugar, que el art. 86 de la LRBRL, todo él (y no sólo el apartado 3 de la versión original, apartado 2 de la versión actual), se refiere a la iniciativa local en ámbitos publificados (reservados); en segundo lugar, que una cosa son los servicios públicos locales (evidentemente, cuando el art. 95, 1 del TRRL habla de los servicios públicos locales se está refiriendo a los servicios mínimos municipales del art. 26 de la LRBRL) y otra cosa distinta son los servicios esenciales reservados. En este trabajo no se comparte ninguna de esas dos premisas, sino que, por un lado, se discrimina dentro del art. 86 de la LRBRL entre la iniciativa pública económica local del apartado 1 y las reservas del apartado 2 (según la numeración que a los apartados del artículo ha dado la LRSAL); y, por otro lado, se parte de la premisa que los servicios públicos económicos no son sino los servicios esenciales reservados.

Sea como fuere el modo en que se interpreta el art. 95, 1, del TRRL parece evidente que fuera del ámbito de los servicios públicos o servicios reservados no es admisible que las actividades económicas que lleven a cabo las entidades locales puedan gestionarse de acuerdo con alguna de las formas indirectas de gestión de los servicios públicos del TRLCSP, por cuanto tal cosa supondría aceptar que para llevar a cabo la actividad hace falta obtener, por ejemplo, una concesión municipal, una consecuencia directamente contraria al principio de libertad de empresa del art. 38 de la CE.

Sólo los servicios públicos locales -y no otras actividades o servicios locales de naturaleza económica, derivados del ejercicio de la iniciativa pública económica local- pueden gestionarse mediante alguna de las formas contempladas en el art. 85, 2, letra B, de la LRBRL, es decir, sólo los servicios públicos locales pueden gestionarse indirectamente. Una interpretación distinta del art. 95, 1, del TRRL, como si admitiese la gestión indirecta no sólo los servicios públicos locales, sino también de otros servicios locales que se establezcan en virtud de la iniciativa pública prevista en el art. 86 LRBRL (la prevista, aunque el art. 95, 1, TRRL no lo dice, en el núm. 1 del art. 86 LRBRL), debe ser rechazada. La reforma llevada a cabo en el art. 86 por la LRSAL no contribuye a aclarar este punto.

\section{LAS MODIFICACIONES EN MATERIA DE RESERVAS LOCALES}

Un precepto clave para el estudio de los servicios públicos locales es el art. 86, 2, LRBRL, que versa sobre la reserva de determinadas actividades y servicios esenciales a favor de las entidades locales. A continuación transcribo la redacción que al precepto ha dado la LRSAL:

«2. Se declara la reserva en favor de las Entidades Locales de las siguientes actividades o servicios esenciales: abastecimiento domiciliario y depuración de aguas; recogida, tratamiento y aprovechamiento de residuos, y transporte público de viajeros, de conformidad con lo previsto en la legislación sectorial aplicable. El Estado y las Comunidades Autónomas, en el ámbito de sus respectivas competencias, podrán establecer, mediante Ley, idéntica reserva para otras actividades y servicios.

La efectiva ejecución de estas actividades en régimen de monopolio requiere, además del acuerdo de aprobación del pleno de la correspondiente Corporación local, la aprobación por el órgano competente de la Comunidad Autónoma».

Como fácilmente se aprecia, el precepto transcrito constituye un trasunto local del concepto constitucional de reserva del art. 128, 2, segunda frase, de la CE, que dice así:

«Mediante ley se podrá reservar al sector público recursos o servicios esenciales, especialmente en caso de monopolio(...)». 
El art. 86, 2, de la LRBRL ha sido interpretado de diversas maneras, tanto por los autores, como por los tribunales. Los debates sobre el concepto constitucional de reserva del art. 128 de la CE se han proyectado sobre su equivalente local (es decir, el art. 86, 2 de la LRBRL).

En la búsqueda de un concepto de servicio público local producía (y produce) perplejidad que haya servicios municipales obligatorios del art. 26 de la LRBRL no relacionados en el art. 86, 2, de la LRBRL, y viceversa. Existe una coincidencia (pero no identidad) entre las actividades y servicios enumerados en el art. 86, 2, primer párrafo, de la LRBRL con los servicios municipales del art. 26 de la LRBRL (facultativos u obligatorios: el precepto va enumerando los servicios en función de la población, de manera que aquellos servicios cuya prestación resulta obligada, por ejemplo, en municipios de más de 50.000 habitantes son, al mismo tiempo, servicios que se pueden prestar o no en municipios con menor población y son, por eso, facultativos).

Otras discusiones han girado en torno al sentido de la necesidad de una aprobación de la Comunidad Autónoma cuando alguna de las actividades o servicios reservados quiere ejecutarse en forma de monopolio (la llamada efectividad de la reserva), de acuerdo con el art. 86, 3, párrafo segundo, LRBRL.

En mi opinión, hay una identidad conceptual entre servicios públicos y servicios esenciales reservados. Entre las características del concepto de servicio público acuñado en España en los tres primeros cuartos del siglo XX destaca la publificación de la actividad en que el servicio consiste, con atribución de la titularidad sobre el servicio a la Administración Pública. Tras la aprobación de la CE en 1978 esa tesis fue mantenida por una parte de la comunidad científica, la cual, por un cierto temor al vacío derivado de la inexistencia de referencia alguna a los servicios públicos económicos en la $\mathrm{CE}^{6}$, vertió la doctrina tradicional del servicio público sobre la reserva de servicios esenciales del art. 128, 2, segunda frase, de la CE. Este sector doctrinal suele afirmar, tras aclarar que el concepto de servicio esencial -a secas- no es identificable con el concepto de servicio público, que los servicios esenciales reservados ocupan el mismo espacio que los servicios públicos tal y como fueron conceptuados en tiempos preconstitucionales. En consecuencia, la reserva comporta tanto la publicatio de la actividad, su titularidad pública, como la libertad de la Administración para gestionar el servicio reservado como estime más conveniente para los intereses generales, directa o indirectamente, con monopolio o sin él; el reverso de esta tesis es que la actividad en que consiste el servicio esencial reservado queda extraída del ámbito de la libre iniciativa económica de los ciudadanos, como una suerte de excepción a la libertad de empresa en una economía de mercado; desde un punto de vista práctico, la única forma al alcance de los particulares para operar en el ámbito reservado es la obtención de una concesión administrativa u otro tipo de contrato de gestión de servicios públicos?.

¿Y qué significado ha de otorgarse a las palabras «especialmente en caso de monopolio» del art. 128, 2, de la CE? Estas palabras significan que un indicio de que el servicio es esencial y de que, por tanto, la ley puede reservarlo al sector público es que se trate de una actividad que tienda naturalmente al monopolio, es decir, que sea un monopolio natural, definido como aquella situación del mercado en que una sola empresa puede producir el output deseado a menor coste que en cualquier combinación de dos o más empresas. Los recursos y los servicios pueden ser esenciales según la consideración de los ciudadanos y de la clase política, pero hasta que la ley no reserva no hay servicio público propiamente dicho. El concepto de servicio esencial es más amplio que el de servicio público, pues éste no es sino un servicio esencial reservado.

La palabra reserva en el art. 128, 2, CE es sinónima de publicatio. Erigir un servicio público es lo mismo que publificar una actividad y es también lo mismo que reservar un servicio. Son expresiones sinónimas. Todo servicio público implica una exclusividad en la titularidad a favor de una Administración. No todo servicio público implica un monopolio de facto, es decir, la gestión del servicio puede estar en manos de particulares. Ambos planos -titularidad y gestión- deben diferenciarse netamente. Aunque la gestión esté en manos de los particulares (v.gr., mediante concesión administrativa), la Administración no pierde la titularidad. La ley que reserva establece el servicio público, lo crea, y no prejuzga el modo en que el servicio va a gestionarse pues la reserva implica más bien la exclusividad a favor del poder público, sin perjuicio de que a posteriori la actividad se conceda a los particulares, se gestione directamente por la Administración de forma monopolística o, por último, se gestione en parte directa y en parte indirectamente. Desde esta perspectiva la palabra «reserva» no significa en el art. 128, 2, CE, gestión directa.

6 En los dos preceptos en que la CE se refiere a los servicios públicos (arts. 106 y 158, 1), ni la ubicación sistemática de los artículos ni la amplitud del significado con que se utiliza, son útiles a los efectos de la identificación del concepto tradicional estricto de servicio público en el nuevo texto constitucional.

7 Por todos, vid. Ariño Ortiz, G., Principios de Derecho Público Económico. Modelo de Estado, Gestión Pública, Regulación Económica, ed.

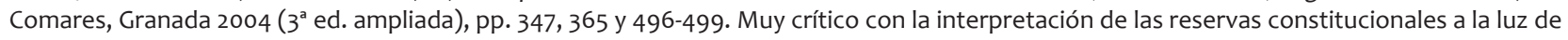
un concepto preconstitucional de servicio público se muestra Troncoso Reigada, A., Dogmática administrativa y derecho constitucional: el caso del servicio público, en «Revista Española de Derecho Constitucional», núm. 57 (1999), pp. 87-164, particularmente pp. 87-98. 
Para quienes mantenemos lo expuesto en los tres párrafos anteriores (a la luz del art. 128, 2 CE), el segundo párrafo del art. 86, 2, LRBRL produce perplejidad: el precepto limita la libertad de organización del servicio por parte de la entidad local, porque exige aprobación autonómica para ejecutar el servicio en régimen de monopolio (aunque se trata de un control de legalidad, no de oportunidad). Así como la reserva del art. 86, 2, primer párrafo, de la LRBRL, es la reserva de que habla el art. 128, 2, segunda frase, CE, la previsión del art. 86, 2, segundo párrafo, de la LRBRL, previsión específica para las entidades locales, es extraña al concepto constitucional de reserva, la cual implica por si misma la posibilidad de ejecución en régimen de monopolio.

Otra parte relevante de la doctrina procuró realizar un nuevo esfuerzo interpretativo del art. 128, 2, segunda frase, de la CE, tratando de deslindarlo del concepto de servicio público; para este sector, el precepto tan sólo sienta los fundamentos constitucionales para que la Administración intervenga en sectores económicos determinados, de manera que junto a los servicios esenciales reservados, con titularidad exclusiva de la Administración, el art. 128, 2, segunda frase, de la CE, contempla también servicios públicos sin esa titularidad'.

En algunos autores parece advertirse que el contenido del art. 86, 2, de la LRBRL se utiliza para interpretar el art. 128 de la CE: a la vista del precepto de la LRBRL afirman que las reservas del art. 128, 2, de la CE no consisten en erigir un servicio público, sino en la decisión de gestionar ese servicio de forma directa por la propia Administración y de forma monopólica. Dada la proximidad temporal entre la CE (1978) y la LRBRL (1985) y dado que el concepto constitucional de reserva (inédito en Derecho español, cuando fue introducido por la CE de 1978) no había sido objeto de desarrollo legislativo antes de 1985 (año de aprobación de la LRBRL), resulta que la forma en que la LRBRL interpretó la reserva de la CE (con todas sus anomalías y errores) se convirtió en una suerte de interpretación auténtica del sentido de la reserva constitucional. Como para la LRBRL la mera declaración legal de que un servicio está reservado no es suficiente para entender que la reserva es efectiva y como sólo la efectividad de la reserva permite que el servicio reservado se gestione de forma monopólica, entonces la reserva constitucional de un servicio no se traduce en la declaración de que ese servicio ha devenido público, sino en que la reserva implica gestión directa y monopólica por la propia Administración Pública. Sólo así se entienden las siguientes afirmaciones: «(...) no se trata sólo de mantener una determinada titularidad pública de algo que ya lo es (...). En el art. 128, 2 CE, por el contrario, el término tiene un significado del todo distinto. Se trata de asumir "con carácter exclusivo", "apartando a los demás" -son expresiones que se recogen en el Diccionario de la Lengua-, una determinada actividad que, por exigencias del interés general, se sustrae a su posible realización por el sector privado»'s.

El TS, en Sentencia de su Sala $3^{\mathrm{a}}\left(\right.$ Sección $7^{\mathrm{a}}$ ) de 21 de diciembre de 2000 ha reconocido expresamente que la efectividad de la reserva no significa gestión directa, sino que el servicio -monopolizado- puede encomendarse a un tercero. Esto es lo que afirma en el Fundamento de derecho núm. 6 (apartado 4):

«Por lo que ya en particular se refiere al ejercicio de actividades o servicios en régimen de monopolio, por parte de las Entidades Locales, la lectura de los artículos 128 de la CE, 86 de la LBRL y 96 y 97 del TRRL permite distinguir, como aspectos o conceptos diferenciados, los siguientes:

- La posibilidad general de reservar al sector público actividades o servicios esenciales, con la consiguiente exclusión respecto de ellos de la titularidad privada, que está prevista en la Constitución, y para la que dicha norma fundamental requiere una específica habilitación legal (al disponer que ha de hacerse “mediante ley").

- La habilitación legal específicamente referida a la reserva en favor de las Entidades locales del servicio esencial de abastecimiento y depuración de aguas, que se encuentra establecida en el artículo 86 de la LBRL.

- La decisión de la Entidad local por la que, ejercitando esa habilitación legal, asume de manera efectiva la responsabilidad sobre la ejecución de la actividad legalmente reservada, para desarrollarla en régimen de monopolio, y que, por ello, impide en lo sucesivo la iniciativa privada que con anterioridad pudiera haber existido sobre esa actividad. Esta decisión requiere cumplir los trámites ordenados en los artículos 86 LBRL y 97 TRRL, y, además, la aprobación del órgano de gobierno de la Comunidad Autónoma.

- La gestión del servicio monopolizado, que puede ser directa o indirecta; y

- La adjudicación a un particular del contrato por el que se encarga de la gestión indirecta del servicio municipal monopolizado».

8 Por todos vid. Muñoz Machado, S., Servicio Público y Mercado. I. Los fundamentos, ed. Civitas, Madrid 1998, especialmente pp. 113-118 (este trabajo consta de tres volúmenes más: II. Las telecomunicaciones, III La televisión y IV. El sistema eléctrico, en la misma editorial y año)

9 Martín-Retortillo, S., Derecho Administrativo Económico, I, ed. La Ley, Madrid 1988, pp. 250-258. La cita está en p. 251. 
A propósito de los arts. 25, 1; 26; 85, 1; y 86, 2, de la LRBRL la mejor doctrina ha tratado de clarificar el panorama relativo a los servicios públicos. La exposición más coherente de lo que significa la reserva local del art. 86, 2, de la LRBRL -como vía para el establecimiento de monopolios locales- se encuentra en el trabajo de Díaz Lema en cuyas páginas se hallan todos los elementos necesarios para comprender el régimen jurídico de los servicios públicos locales y su relación con la iniciativa económica local, expuestos de tal manera que el autor alcanza a construir un sistema inteligible, a pesar de que algunas de las premisas de que parte (concretamente, la identificación del servicio público y de la reserva, con el monopolio) sean discutibles. Por lo demás, la lectura de este trabajo, que se sustenta sobre la base de la distinción entre cuatros conceptos (competencias, servicios mínimos -facultativos y obligatorios-, reserva e iniciativa pública), proporciona al lector las claves para entender, en parte, qué se ha pretendido con la LRSAL. ${ }^{10}$

La reforma operada sobre el art. 86, 2, de la LRBRL por la LRSAL no altera su estructura esencial, pero sí lleva a cabo una nueva y muy significativa reducción del número de servicios reservados y contiene alguna otra modificación de interés. La interpretación del art. 86, 2, de la LRBRL, como precepto que fundamenta el establecimiento de monopolios locales está recogida por la Exposición de Motivos de la LRSAL, que explica la reducción del número de servicios que se pueden reservar de la siguiente manera:

«Finalmente, para favorecer la iniciativa económica privada (...). Asimismo, se suprimen monopolios municipales que venían heredados del pasado y que recaen sobre sectores económicos pujantes en la actualidad».

La versión original del art. 86, 3, de la LRBRL decía así:

"Se declara la reserva en favor de las Entidades locales de las siguientes actividades o servicios esenciales: abastecimiento y depuración de aguas; recogida, tratamiento y aprovechamiento de residuos; suministro de gas y calefacción; mataderos, mercados y lonjas centrales; transporte público de viajeros; servicios mortuorios».

La referencia a los servicios mortuorios fue suprimida por el RD-L núm. 7/1996, de 7 de junio. Por su parte, la Ley de Hidrocarburos de 1998 suprimió la referencia al suministro de gas. Finalmente, la LRSAL suprime las referencias a la calefacción, los mataderos, mercados y lonjas centrales.

La progresiva reducción del número de actividades o servicios que pueden ser objeto de reserva, de acuerdo con el art. 86, 2, de la LRBRL constata un hecho indiscutible: que las reservas de servicios esenciales, como técnica novedosa de la CE de 1978 para la intervención pública en la economía, han caído, en la práctica, en desuso. La CE de 1978 responde a un paradigma económico que estaba siendo sustituido por uno nuevo cuando se aprobó. Adicionalmente, la incorporación de España la UE en 1986, ocho años después de la aprobación de la CE, supuso la progresiva desactivación del art. 128, 2, de la CE, en la parte relativa a las reservas, por su incompatibilidad (en principio) con las libertades económicas comunitarias. Para salvar el concepto de reserva de su desaparición, he propuesto en otro lugar una nueva lectura del precepto constitucional, como aquel que albergaría el concepto de regulación económica, técnica dirigida a solventar los problemas ínsitos a los monopolios naturales ${ }^{11}$.

Como se ve, ahora sólo hay tres servicios susceptibles de ser reservados:

1. abastecimiento domiciliario y depuración de aguas;

2. recogida, tratamiento y aprovechamiento de residuos y

3. transporte público de viajeros.

Una limitación adicional que introduce la LRSAL en el art. 86, 2, de la LRBRL es que esa reserva puede llevarse a cabo «de conformidad con lo previsto en la legislación sectorial aplicable», que es una manera de avisar que la reserva puede no llegar a ser efectiva, es decir, que podría no ejecutarse de forma monopólica, si la legislación pertinente (suministro de agua, transporte de viajeros y residuos) impidiesen tal monopolio. Ahora bien, si de acuerdo con el art. 128, 2 de la CE aquellos servicios esenciales que pueden ser reservados al sector público son aquellos que tienden naturalmente al monopolio, y si se admite (como ha de hacerse) que los servicios esenciales que subsisten como reservados en el art. 86, 2, de la LRBRL constituyen (en la mayoría del ciclo), claros monopolios naturales,

10 Díaz Lema, J.M., Los monopolios locales, ed. Montecorvo, Madrid 1994.

11 Vid. Guayo, I. del, La regulación económica como alternativa en «Revista española de Derecho Administrativo», núm. 130 (2006), pp. 227-254, también publicado con el mismo título en Ariño, G., Cuétara, J.M. de la y Guayo, l. del (editores), «Regulación económica. Lecturas escogidas", ed. Aranzadi/Thomson, Cizur Menor 2012, pp. 183-213. 
entonces no parece que la legislación sectorial goce de margen para impedir que la reserva sea efectiva (por seguir con la terminología del art. 86, 2, de la LRBRL, una terminología que no comparto, según he expuesto en otros lugares de este trabajo).

En la versión original de la LRBRL resultaba extraño que fuese necesaria la aprobación de la Comunidad Autónoma para ejercer en régimen de monopolio unos servicios que la ley reservaba a las entidades locales. Ahora que la reserva se reduce al suministro del agua, residuos y al transporte urbano, esa autorización es todavía más incomprensible, por cuanto se trata de actividades (al menos en las partes más importantes del ciclo) que tienen claros elementos de monopolio natural. Sin embargo, la LRSAL, en ardorosa defensa de la libre competencia, modifica el art. 97 del TRRL, que dice ahora lo siguiente (apréciese que la principal novedad es la necesidad de un informe de la autoridad de competencia):

«Para la ejecución efectiva en régimen de monopolio de las actividades reservadas de acuerdo con lo dispuesto en el artículo 86.2 de la Ley 7/1985, de 2 de abril, Reguladora de las Bases de Régimen Local, se requerirá el cumplimiento de los trámites previstos en el número anterior referidos a la conveniencia del régimen de monopolio y se recabará informe de la autoridad de competencia correspondiente, si bien el acuerdo a que se refiere su apartado d) deberá ser optado por mayoría absoluta del número legal de miembros de la Corporación. Recaído acuerdo de la Corporación, se elevará el expediente completo al órgano competente de la Comunidad Autónoma. El Consejo de Gobierno de ésta deberá resolver sobre su aprobación en el plazo de tres meses. Si se solicitase dictamen del Consejo de Estado o del órgano consultivo superior del Consejo de Gobierno de la Comunidad Autónoma, donde existiese, no se computará el tiempo invertido en evacuar la consulta».

Sorprende que esta misma reforma no se haya introducido en el art. 86, 2, de la LRBRL, y que sólo se haya hecho en el TRRL.

El segundo párrafo del art. 86, 2, de la LRBRL ha sido modificado por la LRSAL. Donde antes se decía que la efectividad de la reserva sería aprobada por «el órgano de gobierno de la Comunidad Autónoma», ahora se dice por el «órgano competente de la Comunidad Autónoma». Una gran parte de la doctrina había criticado que dado que la efectividad de la reserva implicaba su monopolio, la LRBRL debería haber establecido que la decisión correspondiese al órgano legislativo de la Comunidad Autónoma y no que tal efectividad fuese decidida por un acto administrativo del Consejo de Gobierno. Desde esa perspectiva, la reforma no ha mejorado las cosas, sino que las empeora, pues donde antes se exigía una decisión (acto) del Consejo de Gobierno, ahora se exige un acto administrativo, pero no necesariamente del Consejo de Gobierno, sino que puede ser adoptado por un órgano administrativo de jerarquía inferior. La única forma de solventar ese retroceso sería interpretar, un tanto forzadamente, que al referirse ahora al «órgano competente» podría estar apuntando, también, al órgano legislativo competente.

\section{UN INTENTO DE DETERMINACIÓN DE CUÁLES SON LOS SERVICIOS PÚBLICOS LOCALES, TRAS LA REFORMA DE 2013}

La versión original del apartado 1 del art. 85 de la LRBRL establecía lo siguiente: «Son servicios públicos locales cuantos tienden a la consecución de los fines señalados como de la competencia de las Entidades locales». Era una definición amplísima. La Ley núm. 57/2003, de 16 de diciembre, de medidas para la modernización del gobierno local modificó ese precepto, que dice, desde entonces, lo siguiente: «Son servicios públicos locales los que prestan las entidades locales en el ámbito de sus competencias». Se trató de un tímido intento de introducir una claridad en el confuso concepto de servicio público local. Concretamente, se quiso desligar el concepto de servicio público del concepto de competencia, para que la indefinición que rodea el tema de las competencias locales desde la aprobación de la LRBRL no afectase a los servicios públicos.

La estrecha relación entre competencias y servicios públicos, en el ámbito local, ha tenido un expreso reconocimiento en la jurisprudencia, como en la STS de 23 de mayo de 1997 (Sala $3^{\text {a }}$, Sección $4^{\mathrm{a}}$ ), en cuyo Fundamento de Derecho Sexto se afirma lo siguiente:

«El concepto de servicio público, calificado frecuentemente como polisémico, no es ciertamente una categoría dogmática unívoca. En Sentencia de 24 octubre 1989, este Tribunal advierte que ningún Texto Legal da un concepto de servicio público y atiende a una noción estricta de servicio público considerándolo "como actividad cuya titularidad ha sido reservada en virtud de una Ley a la Administración para que ésta la reglamente, dirija y gestione, en forma directa o indirecta, y a través de la cual se preste un servicio al público de manera regular y continua". En este sentido, la actividad que se contempla, de explotación de «Balsas» para el abastecimiento de agua para el riego, no puede considerarse, desde luego, como un 
servicio público de titularidad del Cabildo. Ahora bien, la referida noción, a pesar del supuesto en el que se pronuncia la sentencia citada, es más bien predicable del servicio público en la esfera estatal, en la que aparece íntimamente vinculada a la idea de titularidad, junto a la referida exigencia de Ley formal. El servicio público es así una actividad de prestación de titularidad estatal reconocida por la Ley y que comporta, potencialmente, un derecho excluyente a su prestación. Sin embargo, en el ámbito local, existe una noción de servicio público vinculada a la idea de competencia en sintonía con el reiterado artículo 85 LRBRL, que considera servicios públicos a «cuantos tienden a la consecución de los fines señalados como de la competencia de las entidades locales». Este concepto atiende no tanto a la idea de titularidad como a la de la competencia, de manera que la calificación de una determinada actividad prestacional como de servicio público local no convierte al correspondiente ente local en titular de dicha actividad, ni excluye una eventual prestación a iniciativa de otras Administraciones públicas o a iniciativa de particulares. Así, cabe distinguir entre servicios de titularidad municipal y servicios públicos locales caracterizados: por la declaración formal o "publicatio", la naturaleza prestacional, la necesidad de utilizar un procedimiento o forma de gestión de Derecho público y por el criterio teleológico de servir a fines señalados como de la competencia de la Entidad Local».

La Sentencia del TSJ de las Islas Baleares (Sala de lo contencioso-administrativo), de 29 de octubre de 2010, proporcionó una explicación de la relación entre la competencia que el art. 25 atribuye a los Municipios sobre cementerios y actividades funerarias, la liberalización de los servicios mortuorios y el servicio mínimo obligatorio de cementerios:

«Debe distinguirse entre lo que constituye por un lado el servicio público esencial de cementerio, que engloba la regulación, construcción, cuidado y mantenimiento de las dependencias e instalaciones destinadas a este fin, y de otro, el servicio funerario, incluyendo en ese concepto el traslado de cadáveres $y$ todo el conjunto de posibles prestaciones en relación al fallecimiento de una persona, entierro e incineración de cadáveres».

El servicio funerario, que no el de cementerios, está liberalizado por el Real Decreto Ley 7/1996 de 7 de junio sobre medidas urgentes de carácter fiscal y de fomento y liberalización de la actividad económica, de forma que el ayuntamiento ya no puede prestar los servicios funerarios en régimen de monopolio o de prevalencia sobre el resto de empresas del sector como antaño ocurría en el ejercicio de la actividad de "servicios mortuorios". En esta materia el Ayuntamiento ha de someterse a las reglas de la libre competencia, con la única matización de que es exigible a las empresas que deseen ejercer esa actividad, la obtención previa de una autorización municipal de carácter reglado (art. 22 del RDL 7/1996 ) así como aquellas otras que sean exigibles en materia sanitaria y de transportes. Esa limitación no constituye una vulneración de la libertad de empresa consagrado y regulado en el artículo 38 de la CE , pues en definitiva la liberalización o privatización que contempla el artículo 22 del RD 7/1996 no es completa o absoluta, sino que queda sometida a un régimen de autorización municipal, lo cual no puede esconder la intención de consagrar una posición monopolística por parte del ayuntamiento a través de la imposición de numerosas trabas o dificultades a la hora de autorizar en el término municipal aquella actividad económica, que convierta en ilusoria dicha actividad por su imposible ejercicio.

Dicho ello, el Ayuntamiento en el legítimo ejercicio de una competencia que le es propia, servicios funerarios, puede organizar la prestación de ese servicio, como actividad liberalizada a través de la creación de una empresa pública municipal. A tal efecto ya se ha dicho que son servicios públicos locales aquellos que se prestan por las entidades locales en el ámbito de sus competencias y el artículo 25-2 j) de la LRBRL contempla como competencia municipal los “cementerios y servicios funerarios". Nada impide pues, que la administración local decida prestar de forma directa el servicio funerario, pudiendo hacerlo a través de la constitución de una sociedad mercantil con capital enteramente municipal (STS 1 de febrero de 2002 Ponente Sr. Xiol Ríos). Tampoco nada impide que el Ayuntamiento a través de una empresa pública municipal decida gestionar los servicios de cementerio. Son dos actividades distintas, pero mientras la primera ha de moverse bajo el respeto absoluto al criterio de actividad de libre mercado dada la liberalización del servicio, la segunda, no queda afecta a esa liberalización. $Y$ es por ello que en ningún caso la actividad de servicios funerarios a prestar por una empresa pública municipal si así se acordare, puede irrogarse una actitud monopolística o de 
supremacía en el sector, aprovechando la actividad en materia de gestión de cementerio, que como servicio monopolístico y no liberalizado, puede también prestar la administración a través de una empresa pública municipal».

La definición que el art. 85, 1, LRBRL hace de los servicios públicos locales es muy amplia y el art. 25, 1, LRBRL se refiere al servicio público en términos igualmente amplios. Las referencias de ambos preceptos son tan amplias que carecen realmente de virtualidad definidora y no permite que conozcamos cuáles son los servicios públicos locales en sentido estricto, pues también las actividades o servicios económicos que presten las entidades locales como fruto de su libre iniciativa en el ámbito económico podrían ser considerados a tenor de ambos preceptos como servicios públicos. Es preciso, no obstante, hacer un esfuerzo de identificación de cuáles son en sentido estricto los servicios públicos locales ${ }^{12}$.

El art. 95, 1, del TRRL habla de servicios públicos locales. La norma sólo habla de servicios públicos en este precepto y en el art. 1, que dispone que para el cumplimiento de sus fines los Ayuntamientos tienen plena capacidad jurídica para establecer y explotar servicios públicos (en materia de bienes hay un par de referencias al servicio público, que no son ahora relevantes). Parece claro el art. 95, 1, del TRRL designa como servicios públicos los servicios mínimos del art. 26 y, también, los servicios esenciales reservados del art. 86, 2, de la LRBRL.

¿Cuáles son, en definitiva, los servicios públicos locales? Son servicios públicos locales los servicios cuya titularidad es otorgada por la ley a las entidades locales. Esta afirmación es insuficiente, pero nos permite trazar una primera línea divisoria: no todas las actividades sobre las que las entidades locales tienen competencias son servicios públicos. En efecto, una cosa es la titularidad sobre un servicio y otra es la competencia sobre una materia. La diferencia entre titularidad y competencia explica que distintas Administraciones territoriales ejerzan competencias sobre determinados servicios públicos y que sólo una de ellas sea su titular; esta diferencia autoriza que prescindamos (en esta tarea de búsqueda de cuáles son los servicios públicos locales), de la larga y heterogénea lista de competencias enumeradas en el art. 25 LRBRL. La lista enumera competencias, no servicios públicos, a pesar de que alguna de esas materias coincida con alguno de los servicios públicos locales ${ }^{13}$.

Son servicios públicos locales la práctica totalidad de los servicios mencionados en el art. 26 de la LRBRL y también todas las actividades y servicios reservados del art. 86, 2, párrafo primero, de la LRBRL. Para una comprensión cabal de esta postura es preciso llevar a cabo una comparación de los servicios municipales del art. 26 de la LRBRL, con las actividades y servicios reservados del art. 86, 2, de la LRBRL.

En la versión original de ambos preceptos, todos los servicios y actividades enumerados en el segundo de esos dos preceptos $(86,2)$ se encontraban también en el primero (26), salvo los siguientes: a) depuración de aguas; b) aprovechamiento de residuos, c) suministro de gas, d) calefacción y e) lonjas centrales. El art. 86, 3, primer párrafo, de la versión original de la LRBRL hablaba también de servicios mortuorios, parte de los cuales podían entenderse comprendidos en la referencia al servicio de cementerios del art. 26 de la LRBRL, pero esa referencia fue suprimida por el RDL núm. 7/1996, de 7 de junio. La Ley de Hidrocarburos de 1998 suprimió la referencia al suministro de gas en el art. 86, 3, párrafo primero, de la versión original de la LRBRL.

A la lista de servicios que estaban en la versión original del art. 86, 3, de la LRBRL, pero no en el art. 26 de la LRBRL había que añadir los mataderos, los cuales, en virtud del RDL núm. 7/1996, de 7 de junio, dejaron de estar mencionados en el art. 26 de la LRBRL. Los servicios enumerados en esa lista (letras a, b, d y e, supra) eran (hasta la LRSAL) servicios esenciales reservados, pero que no constituían servicios municipales obligatorios en función de la población. Y la referencia al gas, como he dicho, fue suprimida en 1998.

Tras la LRSAL desaparecen entre los servicios reservados del art. 86, 2, de la LRBRL, los siguientes: calefacción, mataderos, mercados y lonjas centrales. Dado que en el art. 26 de la LRBRL (en la versión que le da la LRSAL de 2013) no hay mención alguna ni a la calefacción ni a los mercados, mataderos y lonjas (los mataderos y lonjas no estaban tampoco mencionados en la versión inmediatamente anterior a la LRSAL; la LRSAL suprime la mención a los mercados del art. 26 LRBRL), ha de entenderse que esas actividades no constituyen ya servicios públicos.

12 Vid. Koninckx Frasquet, A., Comentario a los arts. 85, 85 bis, 85 ter y 86, en Domingo Zaballo, M.J. (coordinador), Comentarios a la Ley

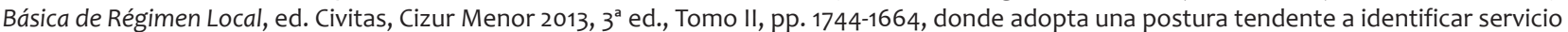
público local y competencia local, con fundamento en alguna jurisprudencia, como la STS de 23 de mayo de 1997 (transcrita en el texto, más adelante).

13 Vid. Montero Pascual, J.J., Servicios Públicos Locales, en Fuentetaja Pastor, J.A. y Fernández Rodríguez, C. (codirectores), Manual de Derecho Local, lustel, Madrid 2013, $2^{\text {a }}$ ed., pp. 403-424; y Rivero Ysern, J.L., Manual de Derecho Local, ed. Civitas, Cizur Menor 2010, 6 ${ }^{\mathrm{a}}$ ed., en particular pp. 425-464 
La supresión de la mención de la calefacción del art. 86, llevada a cabo por la LRSAL, debe conectarse con el escaso (prácticamente nulo) interés de las autoridades españolas por el district heating, sistema de calefacción y/o agua caliente tan extendido en otros países de Europa. Se trata de un sistema que introduce altos grados de eficiencia energética.

Por su parte, el art. 26 LRBRL contiene algunos servicios obligatorios no contemplados entre los reservados del art. 86, 2, párrafo primero, de la LRBRL, a saber:

- $\quad$ en todos los Municipios: alumbrado público, cementerio, limpieza viaria, alcantarillado, acceso a los núcleos de población, pavimentación de las vías públicas;

- $\quad$ en Municipios de más de 5.000 habitantes: parque público y biblioteca pública;

- $\quad$ en Municipios de más de 20.000 habitantes: protección civil, evaluación e información de situaciones de necesidad social y la atención inmediata a personas en situación o riesgo de exclusión social, prevención y extinción de incendios e instalaciones deportivas de uso público; y

- $\quad$ en los Municipios de más de 50.000 habitantes: medio ambiente urbano.

La LRSAL suprime la referencia a «control de alimentos y bebidas» en el art. 26 de la LRBRL. Esto es coherente con la supresión de la referencia a los mercados, mataderos y lonjas y ha de entenderse en el mismo contexto. La supresión, obviamente, no significa que el Ayuntamiento no pueda llevar a cabo actuaciones en esos campos, no ya como servicios públicos, sino en cuanto actuación debida como consecuencia de las competencias del Municipio en materia de «ferias, abastos, mercados, lonjas y comercio ambulante» (art. 25 de la LRBRL, según la redacción que le da la LRSAL). La original referencia a la «protección de los servicios sociales» se ha sustituido por una referencia a la «evaluación e información de situaciones de necesidad social y la atención inmediata a personas en situación o riesgo de exclusión social». El propósito del nuevo circunloquio es decantar los servicios sociales hacia las Comunidades Autónomas. Así queda patente en la Disposición Transitoria Segunda de la LRSAL: a su tenor, con fecha 31 de diciembre de 2015, y en los términos previstos en las normas reguladoras del sistema de financiación autonómica y de las Haciendas Locales, las Comunidades Autónomas habrán de asumir la titularidad de las competencias que se preveían como propias del Municipio, antes de la LRSAL, relativas a la prestación de los servicios sociales y de promoción y reinserción social. Por último, en la versión original se hablaba de «protección del medio ambiente» $\mathrm{y}$, ahora, con un propósito reduccionista, se habla del «medio ambiente urbano».

Todas las actividades enumeradas simultáneamente en uno y otro artículo son servicios públicos locales, es decir, servicios esenciales para los vecinos de los municipios que, por ese carácter esencial, han sido reservados. Los sectores que sólo se encuentran en el art. 26 de la LRBRL pueden ser incluidos en uno de los dos siguientes grupos: o auténticos servicios públicos o ámbitos en el que los municipios han de tener competencias ex LRBRL (en este segundo grupo se encuentran, a mi juicio, la atención inmediata a personas en situación o riesgo de exclusión social protección civil y medio ambiente urbano, es decir, como materias o ámbitos en los cuales los municipios han de tener, de conformidad con lo que señalen las respectivas leyes, competencias). En el primer grupo, todos los demás.

El hecho de que algunos servicios del art. 26 de la LRBRL no estén mencionados entre las actividades o servicios reservados del art. 86, 2, de la LRBRL constituyen sin duda una fuente de perplejidad y el intérprete se siente tentado después de considerar todas las posibles explicaciones, bien a pensar que se trata de un defecto de la LRBRL bien desde una postura un tanto heterodoxa- a considerar la posibilidad de que algunos servicios municipales del art. 26 de la LRBRL que no están reservados expresamente en el art. 86, 2, primer párrafo, de la LRBRL a favor de las entidades locales (como, por ejemplo, alumbrado público, limpieza viaria, alcantarillado, acceso a los núcleos de población y pavimentación de las vías públicas), están reservados por el propio art. 26 de la LRBRL y que en tales servicios no hará falta trámite ulterior ante la Comunidad Autónoma cuando se quieren ejercitar en régimen de monopolio.

La reforma de la LRSAL del art. 86, 2 LRBRL, ahonda en dos tendencias que se perciben en el derecho local desde 1985. Por un lado, las reservas van desapareciendo. Ahora, tras la LRSAL, sólo quedan tres: agua, residuos y transporte; por otro lado, la posición de los entes locales en las reservas queda diferido a lo que disponga la ley sectorial, como dice expresamente la LRBRL, tras la LRSAL: «de conformidad con la legislación sectorial aplicable».

Otra de las razones de la confusión entre las actividades económicas locales y los servicios públicos locales estriba en que el art. 86, 2, primer párrafo, de la LRBRL habla de actividades y servicios reservados, pero la lista no discrimina entre las realidades enumeradas cuáles son actividades y cuáles son servicios. De todas formas, la confusión no origina especiales inconvenientes conceptuales dado que unas (actividades) y otros (servicios) están reservados (publificados). A partir de una determinada interpretación del art. 128, 2, segunda frase, de la CE tanto las actividades como los servicios del art. 86, 2, primer párrafo, de la LRBRL, son servicios públicos. El precepto 
prevé además que futuras leyes autonómicas o estatales amplíen la reserva a otros sectores. Las consecuencias que se siguen de la reserva son las mismas para los servicios reservados que para las actividades reservadas.

En cualquier caso, y con independencia de la confusa terminología, las actividades del art. 86, 2, primer párrafo, de la LRBRL, no son las actividades del art 86,1 , de la LRBRL: aquéllas son actividades reservadas y las segundas son actividades desarrolladas en sectores no reservados. El art. 86, 2, primer párrafo, de la LRBRL habla de actividades y servicios esenciales reservados, pero no se está refiriendo, con la expresión actividades reservadas, a las actividades que la entidad local lleva a cabo en ejercicio de su libre iniciativa económica sino que en el contexto en que se inserta ese precepto se trata de actividades reservadas y de servicios reservados.

Esta parcial asimilación en la legislación entre actividades económicas de la entidad local y sus servicios públicos es perceptible también en el art. 97 del TRRL porque en él se establece un procedimiento común para el ejercicio de ambos tipos de iniciativa, si bien la monopolización de actividades o servicios reservados requiere algunos trámites ulteriores, que son novedosos, pues han sido reformados por la LRSAL según he explicado supra. ${ }^{14}$ Puede añadirse que el art. 95, 1, primera frase, del TRRL incurre en la misma confusión. La iniciativa pública local del art. 86 de la LRBRL (al menos la de su apartado 1 no origina servicios públicos, sino ejercicio de variadas actividades económicas distintas de los servicios públicos).

\section{FUSIÓN DE MUNICIPIOS Y SERVICIOS PÚBLICOS}

El art. 13, 4, letra f, de la LRBRL (según la redacción que le da la LRSAL), dice así:

«Los municipios, con independencia de su población, colindantes dentro de la misma provincia podrán acordar su fusión mediante un convenio de fusión, sin perjuicio del procedimiento previsto en la normativa autonómica. El nuevo municipio resultante de la fusión no podrá segregarse hasta transcurridos diez años desde la adopción del convenio de fusión.

Al municipio resultante de esta fusión le será de aplicación lo siguiente:

(...) f) Queda dispensado de prestar nuevos servicios mínimos de los previstos en el artículo 26 que le corresponda por razón de su aumento poblacional».

Se trata de una medida dirigida a fomentar la fusión de Municipios, que es una de las principales finalidades de la LRSAL.

\section{EL NUEVO PAPEL DE LAS DIPUTACIONES PROVINCIALES}

Otra novedad introducida por la LRSAL en el art. 26 LRBRL es que se establece una preferencia de las Diputaciones Provinciales, sobre las Comunidades Autónomas, para la asistencia a los municipios en el establecimiento y prestación de los servicios mínimos (se suprimen los apartados 2 y 4 de la versión original del art. 26 de la LRBRL, que daban mayor protagonismo a las Comunidades Autónomas). Concretamente, el nuevo apartado 2 del art. 26 LRBRL dispone que en los municipios con población inferior a 20.000 habitantes será la Diputación provincial o entidad equivalente la que coordinará la prestación de los siguientes servicios: a) Recogida y tratamiento de residuos; b) Abastecimiento de agua potable a domicilio y evacuación y tratamiento de aguas residuales; c) Limpieza viaria; d) Acceso a los núcleos de población; e) Pavimentación de vías urbanas; y f) Alumbrado público. ${ }^{15}$

Para coordinar la prestación de esos servicios la Diputación ha de proponer al Ministerio de Hacienda y Administraciones Públicas, con la conformidad de los municipios afectados, la forma de prestación, consistente en la prestación directa por la Diputación o la implantación de fórmulas de gestión compartida a través de consorcios, mancomunidades u otras fórmulas. En su propósito de ahorro de costes, el apartado 2 del art. 26 de la LRBRL continúa diciendo que, para reducir los costes efectivos de los servicios, el Ministerio decide sobre la propuesta formulada que debe contar con el informe preceptivo de la Comunidad Autónoma si es la Administración que ejerce la tutela financiera. El nuevo precepto contiene otras previsiones sobre la asunción de costes y sobre la posibilidad de que sea el Municipio quien decida la forma de gestión. Debe subrayarse que ha desaparecido la posibilidad de que la Comunidad Autónoma exima a los Municipios de la prestación de los servicios mínimos.

14 Vid. epígrafe 6 de este trabajo.

15 Así lo explica la Exposición de Motivos: «Otra de las medidas adoptadas en la Ley es la de reforzar el papel de las Diputaciones Provinciales, Cabildos, Consejos insulares o entidades equivalentes. Esto se lleva a cabo mediante la coordinación por las Diputaciones de determinados servicios mínimos en los municipios con población inferior a 20.000 habitantes». 
Cuando se lleva a cabo una fusión, a las Diputaciones provinciales o entidades equivalentes, en colaboración con la Comunidad Autónoma, les corresponde coordinar y supervisar la integración de los servicios resultantes del proceso de fusión (art. 14, 5, de la LRBRL, según la redacción que le ha dado la LRSAL).

Entre las competencias propias de las Diputaciones se establece en el art. 36, tras la LRSAL, la siguiente:

«c) La prestación de servicios públicos de carácter supramunicipal y, en su caso, supracomarcal y el fomento o, en su caso, coordinación de la prestación unificada de servicios de los municipios de su respectivo ámbito territorial. En particular, asumirá la prestación de los servicios de tratamiento de residuos en los municipios de menos de 5.000 habitantes, y de prevención y extinción de incendios en los de menos de 20.000 habitantes, cuando éstos no procedan a su prestación».

Para reforzar esa competencia, el precepto establece que a las Diputaciones provinciales corresponde asegurar el acceso de la población de la provincia al conjunto de los servicios mínimos de competencia municipal y a la mayor eficacia y economía en la prestación de éstos mediante cualesquiera fórmulas de asistencia y cooperación municipal. Con esa finalidad, las Diputaciones o entidades equivalentes pueden otorgar subvenciones y ayudas con cargo a sus recursos propios.

La LRSAL ha venido a reforzar el papel de las Diputaciones como instancias de integración territorial, precisamente en unos momentos en que se redoblaban las discusiones acerca de esta entidad local.

\section{REFORMAS EN MATERIA DE GESTIÓN DIRECTA DE LOS SERVICIOS PÚBLICOS}

En el año 2003, las dos reformas más significativas en materia de gestión directa de los servicios públicos locales fueron, en primer lugar, que entre las formas posibles que la gestión directa puede adoptar se incluyó la entidad pública empresarial local (EPE), junto a las otras tres formas de gestión directa que contemplaba la versión inicial de la LRBRL (gestión por la propia entidad local, organismo autónomo local y sociedad mercantil local cuyo capital social pertenezca íntegramente a la entidad local) y, en segundo lugar, que el régimen jurídico de los OAs locales y de las EPEs locales quedó referido, parcialmente, a las previsiones que la LOFAGE contempla sobre los organismos autónomos y las entidades públicas empresariales estatales ${ }^{16}$.

La LRSAL se aprueba en un momento de profunda crisis económica y, consiguientemente, de necesidad de reducción del tamaño del sector público para contener el déficit. La Exposición de Motivos de la LRSAL destaca, en materia de entes instrumentales, varias ideas, como las siguientes:

«(...)se incluye una revisión del conjunto de las entidades instrumentales que conforman el sector público local»;

«(...)En ese contexto, se trata de impedir la participación o constitución de entidades instrumentales por las Entidades Locales cuando estén sujetas a un plan económico-financiero o a un plan de ajuste. En cuanto a las existentes que se encuentren en situación deficitaria se les exige su saneamiento, y, si éste no se produce, se deberá proceder a su disolución. Por último, se prohíbe, en todo caso, la creación de entidades instrumentales de segundo nivel, es decir unidades controladas por otras, que, a su vez, lo estén por las Entidades Locales. Esta prohibición, motivada por razones de eficiencia y de racionalidad económica, obliga a la disolución de aquellas que ya existan a la entrada en vigor de la presente norma en el plazo previsto»;

«Asimismo, como medida de transparencia, se establece la obligación de determinar el coste efectivo de los servicios que prestan las Entidades Locales, de acuerdo con criterios comunes».

En materia de entes para la gestión de los servicios públicos, la LRSAL ha venido a decantarse claramente por la gestión directa en la modalidad de gestión directa por la propia entidad local o por organismo autónomo local, en detrimento de la EPE local y la sociedad mercantil local. El legislador entiende que la proliferación de personas jurídicas no es sostenible financieramente. Con ese objeto, se introduce en el apartado 2 del art. 85, el siguiente párrafo:

16 Vid., más ampliamente Guayo Castiella, I. del, La gestión de servicios públicos locales, en «RAP», núm. 165(2004), pp. 87-133. 
"Solo podrá hacerse uso de las formas previstas en las letras c) y d) cuando quede acreditado mediante memoria justificativa elaborada al efecto que resultan más sostenibles y eficientes que las formas dispuestas en las letras a) y b), para lo que se deberán tener en cuenta los criterios de rentabilidad económica y recuperación de la inversión. Además, deberá constar en el expediente la memoria justificativa del asesoramiento recibido que se elevará al Pleno para su aprobación en donde se incluirán los informes sobre el coste del servicio, así como, el apoyo técnico recibido, que deberán ser publicitados. A estos efectos, se recabará informe del interventor local quien valorará la sostenibilidad financiera de las propuestas planteadas, de conformidad con lo previsto en el artículo 4 de la Ley Orgánica 2/2012, de 27 de abril, de Estabilidad Presupuestaria y Sostenibilidad Financiera».

Con carácter general (no sólo, por tanto, para los entes instrumentales específicamente diseñados para la gestión de servicios públicos), la LRSAL contempla el redimensionamiento del sector público local en la Disposición Adicional Novena (una Disposición originalmente dedicada al Observatorio Urbano). La principal preocupación es la simplificación y supresión de estructuras innecesarias. Se propone un específico calendario. Los plazos para el cambio de adscripción, vinculación o dependencia, la disolución y para proceder a la transmisión de la correspondiente participación (contemplados en el apartado 4 de esa DA 9 $9^{\text {) }}$ se amplían en un año más, cuando las entidades en desequilibrio estén prestando, precisamente, alguno de los siguientes servicios esenciales que subsisten en el art. 86, 3, de la LRBRL: abastecimiento domiciliario y depuración de aguas, recogida, tratamiento y aprovechamiento de residuos, y transporte público de viajeros. ${ }^{17}$.

La LRSAL suprime el apartado 3 del art. 85, que decía así:

«En ningún caso podrán prestarse por gestión indirecta ni mediante sociedad mercantil de capital social exclusivamente local los servicios públicos que impliquen ejercicio de autoridad».

Esta supresión no puede ser entendida como si ahora las sociedades mercantiles locales puedan ejercer autoridad o que pueda contratarse un servicio que implique autoridad, sino que esa prohibición sigue operativa, por la remisión que la LRBRL, en materia de gestión indirecta, hace al Real Decreto Legislativo núm. 3/2011, de 14 de noviembre, que aprueba el Texto Refundido de la Ley de Contratos del Sector Público, cuyo art. 275, 1, segunda frase, establece lo siguiente:

«En ningún caso podrán prestarse por gestión indirecta los servicios que impliquen ejercicio de la autoridad inherente a los poderes públicos».

\section{CONCLUSIONES}

En las circunstancias actuales, es lógico que el legislador haya buscado soluciones al grave problema financiero que aqueja a tantas corporaciones locales españolas. Esta preocupación por el déficit y por la reducción y simplificación de estructuras administrativas explica, casi en su totalidad, la finalidad y los objetivos de la LRSAL, pero subraya la necesidad de que se diseñe una nueva Ley de Régimen Local, que aborde todos los problemas que tiene pendiente la vida local española, que son más que los relativos a la sostenibilidad financiera, aun cuando la solución a este problema es, sin duda, un prerrequisito o condicio sine qua non para la solución del resto.

En materia de servicios públicos, la LRSAL ahonda en la reforma iniciada en el año 2003, tendente a deslindar los servicios públicos locales de las competencias locales. En ese contexto debería leerse el nuevo adelgazamiento que se produce en el número de servicios reservados. La disminución de esa lista no debe interpretarse como un desapoderamiento de las entidades locales de control o poder sobre ámbitos antes públicos. Antes al contrario, en la medida en que la efectividad de la reserva requiere aprobación de la Comunidad Autónoma, la reforma habría de entenderse como una profundización en la autonomía local, máxime si se considera que los tres grandes servicios subsistentes entre los servicios reservables (agua, residuos y transporte) están también entre los servicios mínimos municipales obligatorios (o facultativos, en función de la población). La reforma del art. 86 de la LRBRL mediante la LRSAL es un paso más en la clarificación de cuántos y cuáles son los servicios públicos de la responsabilidad de los Ayuntamientos, por cuanto la existencia de una lista de servicios públicos (art. 26 de la LRBRL) y otra lista de servicios reservados (pero no de modo efectivo: art. 86, también de la LRBRL) era más una fuente de confusión (y,

17 Vid. Hurtado López, G., El rediseño y redimensionamiento del sector público económico local, en Santamaría Pastor, J.A. (coordinador), La reforma de 2013 del régimen local español, ed. Fundación Democracia y Gobierno Local, Madrid 2014, pp. 307-337. El calendario se explica en pp. 334-335. Sobre el suministro de agua, vid. López de Castro, L. “La configuración jurídica poliédrica del servicio de abastecimiento de agua a poblaciones”, en: Revista española de Derecho Administrativo, nº 163, 2014, pp. 181-215. 
por ende, de debilitamiento de la posición de las entidades locales v. las Comunidades Autónomas) que una fuente de claridad, ni en la acción administrativa, ni en el ejercicio del derecho de los vecinos a los servicios públicos.

La LRSAL no aporta claridad en la distinción entre servicios públicos de naturaleza económica y actividades económicas que las entidades locales pueden llevar a cabo en ámbitos no publificados. La confusión entre ambos ámbitos de actuación existe desde el momento mismo de aprobación de la LRBRL. Aun cuando la simplificación en la estructura del art. 86 contribuye a clarificar ese punto, son necesarias aún ulteriores reformas, sobre todo en el TRRL. 
